\title{
Associação entre Alimentação Vegetariana e a Prevenção do Câncer Colorretal: Uma Revisão de Literatura
}

\author{
Caroline Topanotti Dagostin, Flavia Karine Rigo², Louyse Sulzbach Damázio³
}

\begin{abstract}
RESUMO
O câncer colorretal representa a neoplasia maligna mais comum do trato gastrointestinal e a terceira causa de morte relacionada ao câncer no mundo. Ele pode ter origem hereditária ou esporádica, sendo esta última responsável por aproximadamente $95 \%$ dos casos. Vários fatores de risco contribuem para o desenvolvimento dessa neoplasia, porém a alimentação parece ser o fator mais influente, pois é capaz de modular a composição da microbiota intestinal. O objetivo deste estudo foi revisar a literatura referente à alimentação e ao desencadeamento do câncer colorretal, a relação de uma dieta rica em carnes no desenvolvimento dessa patologia e investigar a alimentação vegetariana atuando como possível fator de prevenção. O método constitui-se de uma revisão bibliográfica narrativa, realizada a partir de buscas de artigos originais e de revisão. $\mathrm{O}$ alto consumo de carne vermelha e processada pode estar relacionado com o surgimento de câncer colorretal por causar alterações na microbiota, bem como produzir compostos $\mathrm{N}$-nitrosos, aminas aromáticas policíclicas e hidrocarbonetos aromáticos policíclicos, compostos considerados genotóxicos. Além disso, o ferro heme pode elevar a síntese das espécies reativas de oxigênio e estimular a formação endógena de compostos N-nitrosos. A alimentação vegetariana, no entanto, pode ser capaz de prevenir a disbiose e manter a microbiota intestinal saudável em virtude do consumo elevado de alimentos vegetais que disponibilizam fitoquímicos, antioxidantes e anti-inflamatórios, ou seja, potenciais agentes antitumorigênicos. Conclui-se que, mediante mudanças nos hábitos alimentares e comportamentais, torna-se possível retardar ou prevenir o surgimento de câncer.
\end{abstract}

Palavras-chave: Câncer colorretal. DCNT. Plant based. Prevenção. Microbiota intestinal.

ASSOCIATION BETWEEN VEGETARIAN FOOD AND COLORECTAL CANCER PREVENTION: A LITERATURE REVIEW

\section{ABSTRACT}

Colorectal cancer represents the most common malignant neoplasm of the gastrointestinal tract and the third leading cause of cancer-related death in the world. It may be hereditary or sporadic, with the latter accounting for approximately $95 \%$ of cases. Several risk factors contribute to the development of this neoplasia, however, feeding seems to be the most influential factor, since it is able to modulate the composition of the intestinal microbiota. The objective of this study was to review the literature regarding the feeding and triggering of colorectal cancer, the relationship of a high meat diet in the development of this pathology and to investigate the vegetarian diet acting as a possible prevention factor. The method is a narrative bibliographical review, based on original article searches and review. The high consumption of red and processed meat may be related to the appearance of colorectal cancer by causing changes in the microbiota, as well as producing N-nitroso compounds, polycyclic aromatic amines and polycyclic aromatic hydrocarbons, compounds considered genotoxic. In addition, heme iron can elevate the synthesis of reactive oxygen species and stimulate the endogenous formation of $\mathrm{N}$-nitroso compounds. However, vegetarian food may be able to prevent dysbiosis and keep the intestinal microbiota healthy due to the high consumption of plant foods that provide phytochemicals, antioxidants and anti-inflammatories, that is, potential anti-tumorigenic agents. In conclusion that through changes in eating and behavioral habits, it becomes possible to delay or prevent the onset of cancer. Keywords: Colorectal câncer. NCD. Plant based. Prevention. Intestinal microbiota.

RECEBIDO EM: 6/2/2019

MODIFICAÇÕES REQUERIDAS EM: 16/7/2019

ACEITO EM: 28/8/2019

\footnotetext{
Biomédica. Curso de Graduação em Biomedicina. Universidade do Extremo Sul Catarinense. carolinedagostin@hotmail.com

Farmacêutica. Mestre em Ciências Biológicas. Programa de Pós-Graduação em Farmacologia Bioquímica e Molecular. Pós-Doutorado pelo Instituto de Ensino e Pesquisa da Santa Casa de Belo Horizonte vinculado a um projeto de toxinologia da Capes. Universidade do Extremo Sul Catarinense. flakrigo@hotmail.com ${ }^{3}$ Nutricionista. Mestre em Ciências da Saúde. Doutoranda em Ciências da Saúde. Programa de Pós-Graduação em Ciências da Saúde. Universidade do Extremo Sul Catarinense. louyse3@hotmail.com
} 


\section{INTRODUÇÃO}

A alimentação é um dos principais fatores determinantes para a obtenção de uma vida equilibrada e saudável, permitindo manter o organismo humano e animal nutrido e fortalecido. Com o aumento da expectativa de vida, a ocidentalização da dieta e a rotina acelerada, porém, grande parte da população mundial consome diariamente produtos refinados, enlatados e industrializados, e a escolha dos alimentos, na maioria das vezes, é efetuada de forma inconsciente, optando-se pela praticidade. Esses alimentos estão associados ao número crescente de Doenças Crônicas Não Transmissíveis (DCNTs), como obesidade, diabetes mellitus tipo 2 (DM2) e câncer (BOADA; HENRÍQUEZ-HERNÁNDEZ; LUZARDO, 2016).

A carcinogênese é um processo multifatorial que envolve elementos genéticos e ambientais. Os cânceres gastrointestinais, especialmente o colorretal, estão entre os mais frequentes e acredita-se que cerca de $35 \%$ têm como principal motivo a dieta inadequada e o alto consumo de carne vermelha, posto que estes contribuem na patogênese do câncer colorretal (CCR) (BOADA; HENRÍQUEZ-HERNÁNDEZ; LUZARDO, 2016; FRIEDRICH, 2008).

A alimentação vegetariana vem sendo fortemente estudada com o intuito de investigar seus reais impactos sobre o câncer e a possibilidade de a mesma exercer um efeito protetor referente à manifestação do CCR. Existem controvérsias, entretanto, em relação a essa pressuposição e muitos mitos ao redor deste tipo de alimentação (KEY et al., 2009; PARNAUD, CORPET, 1997; SANJOAQUIN et al., 2004). Desse modo, a fim de elucidar os possíveis efeitos das escolhas alimentares sobre o CCR, este trabalho vem com o objetivo de revisar a literatura para melhor avaliar a alimentação vegetariana e sua interação com a mucosa intestinal, a fim de investigar seu provável efeito protetor referente à manifestação do CCR.

\section{METODOLOGIA}

A elaboração deste estudo foi baseada nos fundamentos teóricos e conceitos disponibilizados pelos órgãos oficiais de saúde, literatura e na pesquisa de artigos científicos confiáveis e respeitados no campo da ciência médica.

Este trabalho é uma revisão descritiva da literatura científica que se constitui do estudo da literatura e da interpretação e análise crítica pessoal dos pesquisadores, realizada a partir de buscas de artigos originais e de revisão nas bases de dados Pubmed/ Medline, Bireme, Mendeley e Science Direct relacio- nando CCR e alimentação vegetariana, utilizando as palavras-chave: "colorectal cancer", "vegetarian diet", "prevention" e "meat".

Para a elaboração deste estudo foram utilizados 37 artigos, tendo como critérios de inclusão artigos que abordem a incidência de CCR em vegetarianos e onívoros, os efeitos de uma dieta com alto consumo de alimentos cárneos em relação ao desenvolvimento do CCR e os efeitos da alimentação vegetariana no CCR, considerando sua interação na mucosa colônica. Os critérios de exclusão foram artigos que não abordem nenhum dos assuntos citados anteriormente.

\section{RESULTADO E DISCUSSÃO}

O câncer é caracterizado como um conjunto de patologias crônicas que tem em comum o crescimento e a multiplicação desordenada das células, ocasionadas por falha na informação genética celular (WCRF, 2007). Segundo a American Cancer Society, cerca de 1.735.350 novos casos de câncer deverão ser diagnosticados em 2018 apenas nos Estados Unidos, e aproximadamente 609.640 americanos morrerão por conta dessa patologia, correspondendo a cerca de 1.670 pessoas por dia (ACS, 2018).

Conforme a Organização Mundial da Saúde (OMS), em 2030 espera-se a incidência de 27 milhões de novos casos de câncer e 75 milhões de pessoas vivendo com a doença (INCA, 2016). No Brasil, os cânceres mais incidentes (exceto de pele não melanoma), por localização primária e gênero, esperados para 2018 e 2019, são de próstata, pulmão, cólon e reto, estômago e cavidade oral nos homens; mama, cólon e reto, colo do útero, pulmão e tireoide nas mulheres (INCA, 2017).

O câncer colorretal (CCR) é caracterizado por tumores malignos que acometem o cólon e o reto. $\mathrm{O}$ cólon é a parte inferior do trato intestinal, cuja finalidade é absorver água e sais de alimentos não digeridos (WCRF, 2017). Estes são os locais mais frequentes de neoplasias primárias, podendo originar tanto lesões benignas, os adenomas, quanto malignas, os carcinomas. O CCR representa a neoplasia maligna mais comum do trato gastrointestinal e a terceira causa de morte relacionada ao câncer no mundo (CAMPOS et al., 2017).

De acordo com o Ministério da Saúde, a exposição da mucosa intestinal aos agentes cancerígenos resulta no desenvolvimento de lesões inflamatórias inespecíficas, promovendo alterações celulares. Se, porventura, a agressão for intensa e contínua, desenvolver-se-á a displasia, podendo esta progredir de um 
grau leve a acentuado, resultando no carcinoma in situ (BRASIL, 2003). O CCR divide-se em dois grupos: os hereditários e os esporádicos. Os de origem hereditária correspondem a aproximadamente $5 \%$ das neoplasias e subdividem-se em categorias, nas quais pode haver ou não a presença de pólipos. Já os cânceres esporádicos são aqueles que se desenvolvem a partir de fatores exógenos, não havendo relação com síndromes ou padrão familiar, e correspondem a $95 \%$ do total das neoplasias malignas colorretais (DE CASTRO COTTI et al., 2000; BOADA; HENRÍQUEZ-HERNÁNDEZ; LUZARDO, 2016).

De acordo com a American Cancer Society, os fatores de risco imutáveis que favorecem o CCR são idade acima dos 50 anos, histórico familiar e/ou pessoal de pólipos colorretais ou CCR restabelecido, histórico pessoal de doença inflamatória intestinal (DII), especificamente retocolite ulcerativa inespecífica e doença de Crohn, síndromes hereditárias e DM2. Já nos fatores de risco passiveis de mudança, enquadram-se sobrepeso e obesidade, inatividade física, tabagismo, uso intenso do álcool e certos hábitos alimentares, como o alto consumo de carne vermelha e processada (ACS, 2017).

A alimentação tem forte influência sobre a saúde humana e grande parte pode estar relacionada com a modulação da composição da microbiota intestinal conforme dieta, podendo desempenhar tanto um papel promotor quanto protetor ao desenvolvimento de determinadas patologias (OOSTINDJER et al., 2014). A microbiota consiste em trilhões de microrganismos comensais presentes em vários tecidos do organismo, sendo o cólon a região mais colonizada, apresentando cerca de 160 a 500 espécies diferentes de bactérias com características microbiológicas específicas. Ela desempenha funções essenciais, como o controle da proliferação de bactérias patogênicas presentes no trato gastrointestinal, estimulação do sistema imunológico, regulação da absorção de nutrientes, do metabolismo e fisiologia do hospedeiro, além de influenciar a produção de vitaminas e enzimas e atuar na síntese de compostos necessários para o trofismo da mucosa colônica e para a renovação celular. Qualquer alteração ou desequilíbrio na composição da microbiota é denominada disbiose, podendo ser ocasionada por diversos fatores: administração de antibióticos, estresse ou mudanças na dieta. Esta condição altera as junções intercelulares, responsáveis por manter a integridade da mucosa intestinal e sua permeabilidade, facilitando o acesso de patógenos (TOMASELLO et al., 2016).
O equilíbrio entre a comunidade microbiana intestinal e a produção de metabólitos promotores da saúde, como o butirato, além dos metabólitos carcinogênicos, como os ácidos biliares secundários, influenciam diretamente o desenvolvimento do câncer de cólon. Resíduos de proteínas e ácidos biliares são metabolizados pela microbiota em metabólitos inflamatórios e/ou carcinogênicos, intensificando o risco de progressão neoplásica (KONSTANTINOV, 2017).

A carne é parte complementar da dieta humana e dispõe de uma importante fonte de proteína, ferro, zinco e vitaminas, como niacina, cobalamina e riboflavina. Ela oferece grande biodisponibilidade de nutrientes (CZERWONKA; TOKARZ, 2017), porém, apesar de ser regularmente consumida pela população, estudos sugerem que o alto consumo de carne vermelha (principalmente na sua forma processada) pode estar relacionado ao desenvolvimento de doenças crônicas, como obesidade, DM2, doença cardiovascular e alguns tipos de câncer. Essas doenças apresentam origens multifatoriais, e todas são agravadas pelo processo de inflamação crônica, quando a carne atuaria como um alimento inflamatório. Até então, os fatores envolvidos no desenvolvimento e progressão de tais doenças não puderam ser analisados de forma isolada, porém sabe-se que não se trata apenas de um fator, mas de vários, que podem atuar tanto de forma individual quanto associada a outras condições (SAMRAJ et al., 2014; BOUVARD et al., 2015; BOADA; HENRÍQUEZ-HERNÁNDEZ; LUZARDO, 2016).

Em 2015, a International Agency for Research on Cancer, agência de pesquisa sobre câncer da OMS, classificou o consumo de carne vermelha como provável agente carcinogênico para os seres humanos. Além disso, a carne processada é classificada como evidentemente cancerígena para os seres humanos, baseando-se em comprovações que correlacionem seu consumo ao desenvolvimento de CCR, posto que o consumo diário de uma porção de 50 gramas de carne processada aumenta $18 \%$ o risco de manifestação dessa neoplasia (IARC, 2015).

Estudos indicam que a fermentação anormal do intestino está ligada à obesidade e ao câncer em razão do desequilíbrio da microbiota em virtude do alto consumo de gordura de origem animal. A carne vermelha, por conter alto teor de gordura, atua como um possível fator de risco para o CCR pelas mudanças provocadas na composição da microbiota, uma vez que bactérias redutoras de sulfato intensificam-se e produzem sulfeto de hidrogênio, considerado prejudicial para o epitélio intestinal, especialmente por ocasionar danos ao DNA por meio da produção de radicais 
livres. Esses efeitos estão expostos na Figura 1. A alta ingestão de gordura pode aumentar a quantidade de ácidos biliares primários no cólon que, posteriormente, sofrem transformação a ácidos biliares secundários que são citotóxicos, mutagênicos e antiapoptóticos. 0 dano epitelial pode resultar em uma ativação excessiva de fatores de transcrição ligados à inflamação, como o NF-KB, podendo favorecer a proliferação de células tumorais (OOSTINDJER et al., 2014).

Apesar da composição da microbiota intestinal estar diretamente relacionada com o desenvolvimento de CCR, outros mecanismos foram propostos a fim de explicar a associação entre o consumo de carnes e este tipo de câncer. A carne vermelha refere-se à carne de músculo não processada, envolvendo carne bovina, suína, ovina e outras. A carne processada diz respeito à carne que fora transformada pela adição de sais de cura, fermentação, defumação ou outros processos químicos, a fim de melhorar sua preservação e aspecto (BOUVARD et al., 2015). De acordo com Bouvard et al. (2015), a prática de processar a carne, como curar ou defumar, pode resultar na formação de produtos químicos cancerígenos, entre eles compostos $\mathrm{N}$-nitrosos (NOCs), aminas aromáticas heterocíclicas (HAAs) e hidrocarbonetos aromáticos policíclicos (HAPs). Nitritos e nitratos são sais de cura utilizados na indústria alimentícia, especialmente nos produtos cárneos, a fim de manter a coloração avermelhada e impedir sua deterioração, retardando ações microbianas. Apesar de serem amplamente utilizados pela indústria, estes conservantes apresentam efeitos tóxicos para a saúde humana a longo prazo, tais como a formação de metahemoglobina, que é incapaz de transportar oxigênio e acúmulo dessas substâncias no organismo, provenientes de água, vegetais e outros alimentos consumidos, portanto sua utilização é regularmente monitorada na maioria dos países. $O$ fato é que, além de esses compostos serem ingeridos por meio da dieta, ocorre também formação endógena, particularmente no estômago, quando o nitrito consumido pode reagir com os produtos de degradação de aminoácidos e formar NOCs, como a N-nitrosodimetilamina e monometilnitrosamina, que apresentam efeitos carcinógenos, teratogênicos e mutagênicos (WCRF, 2007; IAMARINO et al., 2015). Além disso, supõe-se que os NOCs, associados ao alto consumo de carne, não podem ser absorvidos pelo intestino delgado, sendo, então, transportados ao intestino grosso, provocando efeitos deletérios nas células epiteliais do cólon (BOADA et al., 2016).

Tanto na carne vermelha quanto na processada, ao serem cozidas diretamente em chama aberta e em altas temperaturas, a gordura é pirolisada, gerando
HAAs e HAPs, que passam a compor a fumaça produzida, sendo, então, absorvidas, e depositam-se na camada mais externa da carne. Esses compostos são genotóxicos e foram associados ao desenvolvimento do CCR em estudos experimentais (BOADA; HENRÍQUEZ-HERNÁNDEZ; LUZARDO, 2016; WCRF, 2017). Os HAPs são metabolizados por enzimas hepáticas em diol-epóxidos que se ligam covalentemente às macromoléculas celulares, inclusive o DNA, provocando erros de replicação e mutações. Há também indicação de que outras reações intermediárias são causadas mediante um processo de oxidação, podendo gerar instabilidade química na alquilação do DNA, ocasionando mutações (MARQUES; VALENTE; ROSA, 2009).

O ferro é um nutriente essencial para a saúde e participa da formação de hemoglobina e mioglobina, bem como dos processos de transporte de oxigênio, produção de enzimas, síntese de DNA, crescimento celular, entre outras funções. Nos alimentos ele está disponível nos tipos heme e não heme. Nos produtos de origem animal, $40 \%$ do ferro presente é do tipo heme e $60 \%$ não heme, portanto o alto consumo de carne e produtos à base de carne podem contribuir para o aumento da absorção desmedida de ferro no organismo, elevando a síntese das espécies reativas de oxigênio (EROs), catalisando a geração de radicais livres no cólon, que podem induzir peroxidação lipídica e danos celulares ao DNA. $O$ excesso de ferro heme presente na carne também demonstrou promover a tumorigênese colorretal por meio da estimulação da formação endógena de NOCs cancerígenos (SILVA et al., 2015; WCRF, 2017).

Figura 1 - Efeito da carne vermelha e processada no desenvolvimento do câncer colorretal

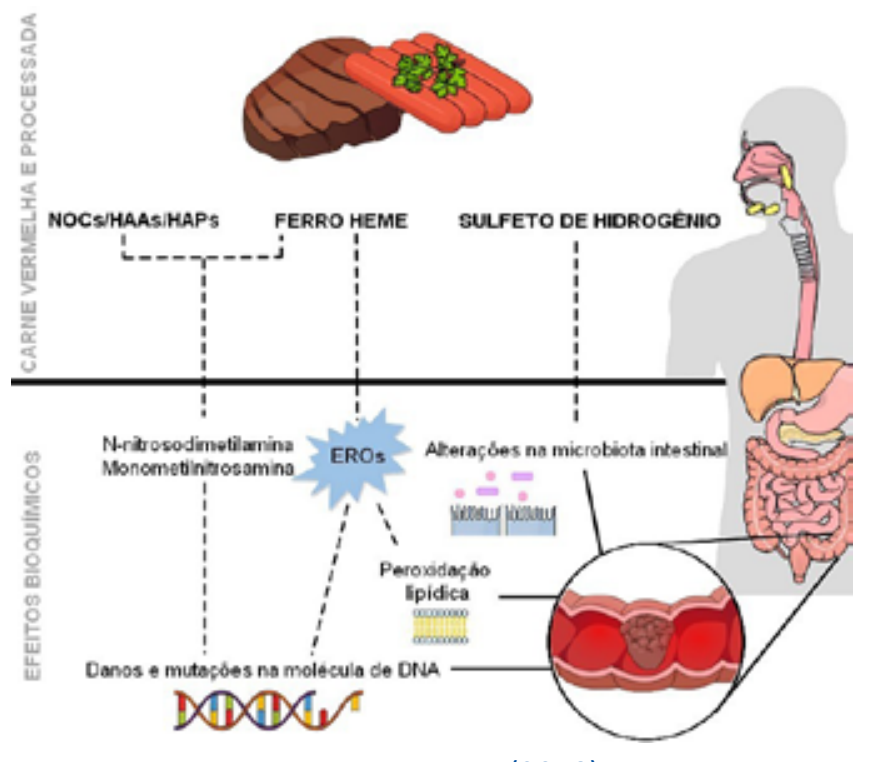

Fonte: As autoras (2018). 
Os compostos individuais presentes na carne podem não ser os únicos responsáveis pelo potencial efeito carcinogênico, e outros agentes modulatórios podem contribuir para o efeito carcinogênico (BOADA; HENRÍQUEZ-HERNÁNDEZ; LUZARDO, 2016).

A alimentação vegetariana é aquela em que se exclui o consumo de carnes e pescado, mas pode incluir ovos e/ou laticínios. Os veganos, além de seguirem a alimentação vegetariana estrita, erradicam também todos os produtos de origem animal e reprovam a utilização de animais como forma de entretenimento (SILVA et al., 2015). Indivíduos que seguem uma alimentação vegetariana geralmente consomem maior quantidade de fibras em comparação com outras dietas, por conta de priorizarem uma alimentação à base de plantas, frutas, vegetais, cereais integrais, leguminosas, produtos à base de soja, nozes e sementes, que são todas ricas em fibras e fitoquímicos, além de consumirem pequena quantidade de gordura saturada, o que contribui para a redução do risco de doenças crônicas (MELINA; CRAIG; LEVIN, 2016).

Considera-se que uma dieta rica em gordura e carboidratos e pobre em frutas e vegetais aumenta o risco de distúrbios metabólicos. Além disso, acredita-se que a alimentação influencia em $57 \%$ a composição da microbiota, enquanto fatores genéticos influenciam apenas $12 \%$. $O$ consumo a longo prazo de grande quantidade de açúcar e gordura provoca disbiose e aumenta a produção de endotoxinas, além de modificar a mucosa intestinal, tornando-a mais fina e permeável a patógenos e antígenos, consequentemente levando a uma inflamação de baixo grau persistente. Por outro lado, uma dieta com alto consumo de vegetais e fibras reduz o $\mathrm{pH}$ intestinal e impede o crescimento de potenciais bactérias patogênicas (TOMASELLO et al., 2016).

Em 2013 analisou-se a relação entre padrões alimentares e a incidência geral de câncer por meio de 69.120 participantes do Adventist Health Study-2. Obteve-se uma associação significante entre a alimentação ovo-lacto-vegetariana e a proteção contra os cânceres do trato gastrointestinal; já a alimentação vegetariana estrita pareceu conferir proteção à incidência geral de câncer (TANTAMANGO-BARTLEY et al., 2012).

A dieta mediterrânea parece ser considerada adequada para a prevenção ou melhora das doenças intestinais, posto que esta é caracterizada pela redução da ingestão de alimentos de origem animal e alto consumo de frutas e vegetais (ricos em fibras, antioxidantes e vitaminas), azeite (rico em ácidos graxos mono e poli-insaturados), grãos integrais e nozes que, em conjunto, fornecem nutrientes como vitamina $D$, ácidos graxos essenciais, minerais e fibras. Esses alimentos podem prevenir a disbiose e, consequentemente, a DII, mantendo a microbiota intestinal saudável. Acredita-se que suplementos alimentares com probióticos atuam no regresso da eubiose intestinal. Além disso, alimentos prebióticos, contendo fibra solúvel, ajudam a manter a eubiose (SILVA et al., 2015; TOMASELLO et al., 2016).

Diversos estudos relacionam a alimentação vegetariana com a baixa incidência geral de câncer (Tabela 1), sobretudo o colorretal, uma vez que, entre os fatores ambientais que induzem o surgimento desta neoplasia, a alimentação destaca-se entre os casos esporádicos, sendo estes os predominantes (SANTOS, 2012). Orlich et al. (2015) avaliaram a associação entre a alimentação vegetariana e o CCR incidente por meio de um estudo prospectivo de coorte norte-americana ao longo de 7 anos. Constatou-se que os padrões alimentares vegetarianos estão relacionados a um menor risco de CCR e atesta-se que estes podem ser importantes na prevenção primária deste tipo de câncer. Em contrapartida, um estudo de coorte comparou a dieta vegetariana (ou com baixa ingestão de carne) com uma dieta rica em carne sobre a influência do risco de desenvolvimento de CCR. Verificou-se que não houve um risco significativamente reduzido para vegetarianos e consumidores de peixe em $1 \mathrm{dia} / \mathrm{sema}$ na em comparação aos consumidores de carne em 6 a 7 dias/semana (GILSING et al., 2015).

Uma revisão sistemática e meta-análise de estudos prospectivos observacionais foi realizada em 2011 por Aune et al. (2013), a fim de investigar a associação entre o consumo de fibras e grãos integrais e o risco de CCR. Foi encontrada, então, uma redução de $10 \%$ no risco deste câncer pelo consumo de 10 gramas por dia e uma redução de cerca de $20 \%$ para 90 gramas por dia (AUNE et al., 2013 ). Em contraste, alguns estudos consideram que o consumo de frutas, vegetais e fibras não parecem conferir proteção para o CCR, com exceção das leguminosas (MICHELS et al., 2000; TERRY et al., 2001).

A alimentação vegetariana proporciona a ingestão de uma ampla diversidade de nutrientes, além de conter substâncias fitoquímicas capazes de proteger as células por suas propriedades antioxidantes, anti-inflamatórias e antiproliferativas. Essa proteção pode ser ampliada pela atuação sinérgica de vários fitoquímicos, tornando sua utilização mais importante na proteção da saúde do que na obtenção de seus nutrientes (SILVA et al., 2015). 
Tabela 1 - Sumário de estudos sobre alimentação vegetariana e câncer colorretal

\begin{tabular}{|c|c|c|c|c|c|c|}
\hline ANO & AUTOR & MÉTODO & OBJETIVO & TEMPO & $\mathbf{N}$ & RESULTADO \\
\hline 2003 & $\begin{array}{c}\text { BINGHAM, Sheila } \\
\text { A. et al. }\end{array}$ & $\begin{array}{c}\text { Estudo } \\
\text { prospectivo }\end{array}$ & $\begin{array}{c}\text { Analisar a relação entre } \\
\text { o consumo de fibras e } \\
\text { a incidência de CCR por } \\
\text { meio de um questionário } \\
\text { alimentar. }\end{array}$ & 6 anos & 5.19978 & $\begin{array}{l}\text { A população, dobrando o } \\
\text { consumo de fibras alimentares, } \\
\text { seria possível reduzir o risco de } \\
\text { CCR em } 40 \% \text {. }\end{array}$ \\
\hline 2011 & $\begin{array}{l}\text { AUNE, Dagfinn } \\
\text { et al. }\end{array}$ & $\begin{array}{c}\text { Revisão } \\
\text { sistemática e } \\
\text { meta-análise } \\
\text { de estudos } \\
\text { prospectivos } \\
\text { observacionais }\end{array}$ & $\begin{array}{l}\text { Investigar a associação } \\
\text { entre o consumo de } \\
\text { fibra alimentar e grãos } \\
\text { integrais e o risco de CCR. }\end{array}$ & & & $\begin{array}{c}\text { A alta ingestão de fibra } \\
\text { alimentar, em especial fibras } \\
\text { de cereais e grãos integrais, foi } \\
\text { associada a um risco reduzido } \\
\text { de CCR. }\end{array}$ \\
\hline 2013 & $\begin{array}{l}\text { TANTAMANGO- } \\
\text { BARTLEY, Y. et al. }\end{array}$ & $\begin{array}{c}\text { Estudo } \\
\text { prospectivo }\end{array}$ & $\begin{array}{c}\text { Analisar a associação } \\
\text { entre padrões } \\
\text { alimentares e a incidência } \\
\text { geral de câncer por meio } \\
\text { de um questionário } \\
\text { alimentar. }\end{array}$ & 4 anos & 69.120 & $\begin{array}{l}\text { A alimentação vegetariana } \\
\text { estrita parece conferir menor } \\
\text { risco de câncer geral, enquanto } \\
\text { as ovo-lacto-vegetarianas } \\
\text { parecem conferir proteção } \\
\text { contra o câncer do trato } \\
\text { gastrointestinal. }\end{array}$ \\
\hline 2015 & $\begin{array}{l}\text { ORLICH, Michael } \\
\text { J. et al. }\end{array}$ & $\begin{array}{c}\text { Estudo } \\
\text { prospectivo }\end{array}$ & $\begin{array}{l}\text { Avaliar a associação entre } \\
\text { alimentação vegetariana } \\
\text { e CCR incidente, por } \\
\text { intermédio de um } \\
\text { questionário quantitativo } \\
\text { de frequência alimentar. }\end{array}$ & 7 anos & $\begin{array}{l}77.659 \\
\text { sendo } 40.367 \\
\text { vegetarianos } \\
\text { e } 37.292 \\
\text { onívoros }\end{array}$ & $\begin{array}{l}\text { As dietas vegetarianas estão } \\
\text { associadas a uma incidência } \\
\text { global menor de CCR. Os } \\
\text { indivíduos que consomem } \\
\text { apenas peixes, em particular, } \\
\text { têm um risco menor em } \\
\text { comparação com os não } \\
\text { vegetarianos. }\end{array}$ \\
\hline 2015 & $\begin{array}{l}\text { GILSING, Anne } \\
\text { M. J. et al. }\end{array}$ & $\begin{array}{l}\text { Estudo } \\
\text { de coorte } \\
\text { populacional }\end{array}$ & $\begin{array}{l}\text { Examinar como uma } \\
\text { dieta vegetariana ou com } \\
\text { pouca carne influencia o } \\
\text { risco de CCR comparando } \\
\text { a uma dieta rica em } \\
\text { carne, por meio de um } \\
\text { questionário alimentar } \\
\text { e outros fatores de risco } \\
\text { potenciais para o câncer. }\end{array}$ & 20 anos & $\begin{array}{c}10.210, \\
\text { sendo } 635 \\
\text { vegetarianos, } \\
360 \\
\text { pescetarianos } \\
\text { e } 9.215 \\
\text { onívoros }\end{array}$ & $\begin{array}{l}\text { Observou-se um risco não } \\
\text { significativamente diminuído } \\
\text { de CRC para vegetarianos, } \\
\text { consumidores de peixe e } 1 \text { dia/ } \\
\text { semana em comparação com } \\
\text { consumidores de carne 6-7 } \\
\text { dias/semana. }\end{array}$ \\
\hline 2015 & $\begin{array}{l}\text { FILIPPIS, } \\
\text { Francesca de } \\
\text { et al. }\end{array}$ & $\begin{array}{l}\text { Estudo } \\
\text { transversal }\end{array}$ & $\begin{array}{l}\text { Investigar os benefícios } \\
\text { da dieta mediterrânea, } \\
\text { avaliando a microbiota } \\
\text { intestinal e o } \\
\text { metaboloma em relação } \\
\text { às suas dietas habituais. }\end{array}$ & 7 dias & $\begin{array}{l}153, \text { sendo } 51 \\
\text { vegetarianos, } \\
51 \text { veganos e } \\
51 \text { onívoros }\end{array}$ & $\begin{array}{c}\text { O consumo de alto nível } \\
\text { de alimentos vegetais está } \\
\text { associado a perfis metabólicos } \\
\text { benéficos relacionados ao } \\
\text { microbioma em indivíduos } \\
\text { consumidores da dieta } \\
\text { ocidental. }\end{array}$ \\
\hline 2016 & $\begin{array}{l}\text { TOMASELLO, } \\
\text { Giovanni et al. }\end{array}$ & $\begin{array}{l}\text { Revisão de } \\
\text { literatura }\end{array}$ & $\begin{array}{c}\text { Elucidar a influência da } \\
\text { dieta sobre a composição } \\
\text { da microbiota intestinal } \\
\text { levando à disbiose e } \\
\text { doença inflamatória } \\
\text { intestinal. }\end{array}$ & & & $\begin{array}{l}\text { A dieta ocidental pode levar à } \\
\text { disbiose grave. Em contraste, } \\
\text { as dietas mediterrânicas e } \\
\text { vegetarianas são conhecidas } \\
\text { por seus efeitos anti- } \\
\text { inflamatórios e podem } \\
\text { prevenir a disbiose e a doença } \\
\text { inflamatória intestinal. }\end{array}$ \\
\hline 2017 & $\begin{array}{l}\text { SINGH, Rasnik K. } \\
\text { et al. }\end{array}$ & $\begin{array}{l}\text { Revisão } \\
\text { sistemática }\end{array}$ & $\begin{array}{c}\text { Avaliar os dados atuais } \\
\text { sobre os efeitos de vários } \\
\text { componentes dietéticos } \\
\text { comuns na microbiota } \\
\text { intestinal. }\end{array}$ & & & $\begin{array}{l}\text { A dieta pode modificar a } \\
\text { microbiota intestinal, dispondo } \\
\text { um impacto profundo na saúde } \\
\text { geral. }\end{array}$ \\
\hline 2018 & $\begin{array}{c}\text { MENG, } \\
\text { Changting et al. }\end{array}$ & $\begin{array}{l}\text { Revisão de } \\
\text { literatura }\end{array}$ & $\begin{array}{l}\text { Revisar a influência da } \\
\text { microbiota intestinal } \\
\text { nos cânceres do trato } \\
\text { gastrointestinal e a } \\
\text { regulação da microbiota } \\
\text { por dieta. }\end{array}$ & & & $\begin{array}{l}\text { A microbiota intestinal está } \\
\text { intimamente relacionada aos } \\
\text { cânceres gastrointestinais. }\end{array}$ \\
\hline
\end{tabular}

Fonte: As autoras (2018). 
A retirada de produtos de origem animal da alimentação não representa que esta se tornará mais saudável, pois, se mal planejada, a alimentação vegetariana pode ser nutricionalmente carente, além de fornecer maior quantidade de gordura, calorias e sal se produtos processados forem consumidos habitualmente, porém acredita-se que vegetarianos possuem um estilo de vida mais consciente de saúde e são menos propensos a fumar e beber excessivamente (RICHI et al., 2015; SILVA et al., 2015).

O consumo de frutas e vegetais disponibiliza potenciais agentes antitumorigênicos e antioxidantes, pois possui compostos bioativos como carotenoides, vitaminas $C$ e E, selênio, ácido fólico, flavonoides, fenóis e limoneno, capazes de inibir danos celulares. Há indícios de que a vitamina $C$ exerce um efeito protetor sobre o desenvolvimento do CCR por ser um potente antioxidante e atua na redução dos níveis de EROs, inibindo a peroxidação lipídica e reduzindo os nitratos. Os grãos integrais são fontes de fibra dietética e são fermentados no intestino, formando ácidos graxos de cadeia curta, como o butirato, e são capazes de restringir o risco de CCR por meio da redução do tempo de trânsito intestinal e do aumento do volume fecal, fazendo com que sua interação com a mucosa do cólon seja breve, consequentemente reduzindo o potencial mutagênico (WCRF, 2017).

O ferro disponível nos alimentos de origem vegetal é do tipo não heme, e sua biodisponibilidade é influenciada por diversos componentes da dieta que podem aumentar ou reduzir sua absorção. A carência de ferro no organismo causa redução do nível sérico das reservas deste mineral, podendo ocasionar anemia por deficiência de ferro, porém, quando a ingestão é combinada principalmente com vitamina $C$, vitamina A e betacaroteno, a absorção do ferro não heme torna-se facilitada. De acordo com a OMS, a deficiência nutricional de ferro é a mais comum no mundo e ocorre tanto em pessoas vegetarianas quanto em não vegetarianas (SILVA et al., 2015).

Vários fatores contribuem para o desenvolvimento do CCR e a alimentação é um fator ambiental certamente associado. Muitos metabólitos produzidos pela microbiota intestinal podem apresentar propriedades tumorigênicas ou anti-tumorigênicas. A alimentação, a microbiota intestinal e a saúde estão intimamente ligadas, e quando harmoniosas, desempenham importantes funções imunes e metabólicas, consequentemente protegendo o organismo de distúrbios que podem promover futuras patologias (MENG et al., 2018).

\section{CONCLUSÃO}

Com base nos estudos aqui citados, conclui-se que a alimentação possui uma importante associação no desenvolvimento de lesões colorretais. O hábito de manter uma alimentação rica em frutas, verduras, hortaliças e cereais integrais, combinada com a baixa (ou nenhuma) ingestão de carnes, a redução do consumo de bebidas alcoólicas, a erradicação do fumo e a prática regular de exercícios físicos, é capaz de possibilitar benefícios à saúde geral e, consequentemente, promover um estilo de vida saudável, portanto sugere-se que por meio de mudanças nos hábitos alimentares e comportamentais, torna-se possível retardar ou prevenir o surgimento de câncer.

Salienta-se que os benefícios da alimentação vegetariana não devem ser considerados observando-se apenas um alimento, mas, sim, o conjunto de vários produtos de origem vegetal atuando sinergicamente. Propõe-se que novas pesquisas sejam realizadas a fim de, gradativamente, se compreender mais satisfatoriamente a atuação dos alimentos vegetais sobre a mucosa intestinal, com o objetivo de obter-se novas teorias e descobertas quanto a sua associação ao CCR, posto que é notável a importância de uma alimentação consciente nos estágios antecedentes de carcinoma.

\section{REFERÊNCIAS}

ACS. American Cancer Society, Inc. All rights reserved. 2018. The American Cancer Society is a qualified 501(c) (3) tax-exempt organization. Available from: https://cancerstatisticscenter.cancer.org/\#!/. Cited: 23 Mar. 2018.

ACS. American Cancer Society, Inc. All rights reserved. 2017. The American Cancer Society is a qualified 501(c) (3) tax-exempt organization. Available from: https://www.cancer. org/cancer/colon-rectal-cancer/causes-risks-<prevention/ risk-factors.html. Cited: 2 Sept. 2017.

AUNE, Dagfinn et al. Red and processed meat intake and risk of colorectal adenomas: a systematic review and meta-analysis of epidemiological studies. Cancer Causes \& Control, [s.I.], v. 24, n. 4, p. 611-627, Feb. 2013.

BINGHAM, Sheila A. et al. Dietary fibre in food and protection against colorectal cancer in the European Prospective Investigation into Cancer and Nutrition (EPIC): an observational study. The Lancet, [s.I.], v. 361, n. 9.368, p. 1.4961.501, May 2003.

BOADA, Luis D.; HENRÍQUEZ-HERNÁNDEZ, L. A.; LUZARDO, $O$. P. The impact of red and processed meat consumption on cancer and other health outcomes: Epidemiological evidences. Food And Chemical Toxicology, [s.I.], v. 92, p. 236244, June 2016.

BOUVARD, Véronique et al. Carcinogenicity of consumption of red and processed meat. The Lancet Oncology, [s.I.], v. 16, n. 16, p. 1.599-1.600, Dec. 2015. 
BRASIL. Ministério Da Saúde. Falando sobre câncer de intestino. Rio de Janeiro: Instituto Nacional de Câncer, 2003. $36 \mathrm{p}$.

CAMPOS, Fábio Guilherme C. M. de et al. Incidence of colorectal cancer in young patients. Revista do Colégio Brasileiro de Cirurgiões, [s.l.], v. 44, n. 2, p. 208-215, Apr. 2017.

CZERWONKA, Małgorzata; TOKARZ, Andrzej. Iron in red meat-friend or foe. Meat Science, [s.I.], v. 123, p. 157-165, Jan. 2017.

DE CASTRO COTTI, Guilherme Cutait et al. Genética do câncer colorretal. Revista de Medicina, São Paulo, v. 79, n. 2-4, p. 65-72, Dec. 2000.

FILIPPIS, Francesca de et al. High-level adherence to a Mediterranean diet beneficially impacts the gut microbiota and associated metabolome. Gut, [s.l.], v. 65, n. 11 , p. 1.812 1.821, 28 Sept. 2015.

FRIEDRICH, Roberta Roggia. A influência da alimentação no câncer colorretal. 2008. 51f. Monografia (Especialização) Universidade Federal do Rio Grande do Sul, Curso de Medicina, Porto Alegre, 2008.

GILSING, Anne M. J. et al. Vegetarianism, low meat consumption and the risk of colorectal cancer in a population based cohort study. Scientific Reports, [s.I.], v. 5, n. 1, p. 1-12, Aug. 2015. DOI: 10.1038/srep13484

IAMARINO, Luciana Zancheta et al. Nitritos e nitratos em produtos cárneos enlatados e/ou embutidos. Gestão Foco, v. 7, p. 246-251, 2015.

IARC. International Agency for Research on Cancer. Monographs evaluate consumption of red meat and processed meat. Lyon:. World Health Organization, Oct. 2015.

INCA. Instituto Nacional de Câncer José Alencar Gomes da Silva. Consenso nacional de nutrição oncológica. 2. ed. rev. ampl. atual. Rio de Janeiro: Inca, 2016.

INCA. Instituto Nacional de Câncer José Alencar Gomes da Silva. Estimativa 2018: incidência de câncer no Brasil. Coordenação de Prevenção e Vigilância. Rio de Janeiro: Inca, 2017.

KEY, Timothy J. et al. Cancer incidence in vegetarians: results from the European Prospective Investigation into Cancer and Nutrition (EPIC-Oxford). The American Journal Of Clinical Nutrition, [s.I.], v. 89, n. 5, p. 1.620-1.626, Mar. 2009.

KONSTANTINOV, Sergey R. Diet, microbiome, and colorectal cancer. Best Practice \& Research Clinical Gastroenterology, [s.I.], v. 31, n. 6, p. 675-681, Dec. 2017.

MARQUES, Anne y Castro; VALENTE, Tessa Bitencourt; ROSA, Cláudia Severo da. Formação de toxinas durante o processamento de alimentos e as possíveis consequências para o organismo humano. Revista de Nutrição, [s.I.], v. 22, n. 2, p. 283-293, Apr. 2009.

MELINA, Vesanto; CRAIG, Winston; LEVIN, Susan. Position of the Academy of Nutrition and Dietetics: Vegetarian Diets. Journal Of The Academy Of Nutrition And Dietetics, [s.I.], v. 116, n. 12, p. 1.970-1.980, Dec. 2016.

MENG, Changting et al. Human Gut Microbiota and Gastrointestinal Cancer. Genomics, Proteomics \& Bioinformatics, [s.I.], v. 16, n. 1, p. 33-49, Feb. 2018.
MICHELS, K. B. et al. Prospective Study of Fruit and Vegetable Consumption and Incidence of Colon and Rectal Cancers. Journal of The National Cancer Institute, [s.I.], v. 92, n. 21, p. 1.740-1.752, 1ㅇ Nov. 2000.

OOSTINDJER, Marije et al. The role of red and processed meat in colorectal cancer development: a perspective. Meat Science, [s.I.], v. 97, n. 4, p. 583-596, Aug. 2014.

ORLICH, Michael J. et al. Vegetarian Dietary Patterns and the Risk of Colorectal Cancers. Jama Internal Medicine, [s.l.], v. 175, n. 5, p. 767-776, May 2015.

PARNAUD, Géraldine; CORPET, Denis E. Cancer colorectal: le rôle controversé de la consommation de viande. Bulletin du cancer, v. 8, n. 9, p. 899-911, 1997.

$\mathrm{RICHI}$, Evelyne Battaglia et al. Health Risks Associated with Meat Consumption: A Review of Epidemiological Studies. International Journal For Vitamin And Nutrition Research, [s.l.], v. 85, n. 1-2, p. 70-78, Dec. 2015.

SAMRAJ, Annie N. et al. A red meat-derived glycan promotes inflammation and cancer progression. Proceedings of The National Academy of Sciences, [s.I.], v. 112, n. 2, p. 542547, Dec. 2014.

SANJOAQUIN, M. A. et al. Nutrition, lifestyle and colorectal cancer incidence: a prospective investigation of 10998 vegetarians and non-vegetarians in the United Kingdom. British Journal of Cancer, [s.l.], v. 90, n. 1, p. 118-121, Jan. 2004.

SANTOS, Rafaela Alcântara dos. Câncer colo-retal: tipos, estágios, marcadores e tratamento. 2012. 36f. TCC (Graduação) - Curso de Farmácia, Universidade Católica de Brasília, Brasília, 2012.

SILVA, Sandra Cristina Gomes et al. Linhas de orientação para uma alimentação vegetariana saudável. Lisboa: Direção Geral da Saúde, 2015.

SINGH, Rasnik K. et al. Influence of diet on the gut microbiome and implications for human health. Journal of Translational Medicine, [s.I.], v. 15, n. 1, p. 73, 8 Apr. 2017.

TANTAMANGO-BARTLEY, Y. et al. Vegetarian Diets and the Incidence of Cancer in a Low-risk Population. Cancer Epidemiology Biomarkers \& Prevention, [s.I.], v. 22, n. 2, p. 286294, Nov. 2012.

TERRY, P. et al. Fruit, Vegetables, Dietary Fiber, and Risk of Colorectal Cancer. Jnci Journal Of The National Cancer Institute, [s.I.], v. 93, n. 7, p. 525-533, Apr. 2001.

TOMASELLO, Giovanni et al. Nutrition, oxidative stress and intestinal dysbiosis: Influence of diet on gut microbiota in inflammatory bowel diseases. Biomedical Papers, [s.I.], v. 160, n. 4, p. 461-466, Dec. 2016.

WCRF. World Cancer Research Fund; American Institute for Cancer Research. Food, nutrition, physical activity, and the prevention of cancer: a global perspective. Amer Inst for Cancer Research, 2007.

WCRF. World Cancer Research Fund International; American Institute for Cancer Research. Continuous Update Project Report: Diet, Nutrition, Physical Activity and Colorectal Cancer. Amer Inst for Cancer Research, 2017. 